\title{
Effect on temporary protection and adhesion promoter of silane nanofilms applied on electro-galvanized steel
}

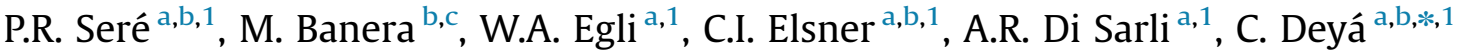 \\ a CIDEPINT: Centro de Investigación y Desarrollo en Tecnología de Pinturas (CICPBA-CONICET LA PLATA), Av. 52 s/n entre 121 y 122,1900 La Plata, Argentina \\ ${ }^{\mathrm{b}}$ Facultad de Ingeniería, Universidad Nacional de La Plata, Av. 1 Esq. 47, 1900 La Plata, Argentina \\ ' INIFTA: Instituto de Investigaciones Fisicoquímicas Teóricas y Aplicadas (UNLP- CONICET LA PLATA), Calle 64 y diagonal $113 \mathrm{~s} / \mathrm{n}$, 1900 La Plata, Argentina
}

\section{A R T I C L E I N F O}

\section{Article history:}

Accepted 25 November 2015

Available online 2 December 2015

Keywords:

Electro-galvanized steel

Temporary protection

Adhesion

Sol-gel pretreatment

\begin{abstract}
A B S T R A C T
In this paper, the effectiveness of $\gamma$-mercaptopropyltrimethoxysilane (MTMO) films as temporary corrosion protection and adhesion promoter on electro-galvanized steel was studied. The films were synthesized from hydrolyzed MTMO with ethanol or methanol, applied by immersion on electro-galvanized steel and cured under different conditions. The porosity of the coating was evaluated by cyclic voltammetry, the corrosion behavior by polarization curves and the protection degree by exposure in the humidity and prohesion chambers. The films were characterized by scanning electron microscopy (SEM) and energy dispersive spectroscopy (EDS). From the obtained experimental results, it was concluded that this protection is markedly affected by the coating curing conditions and the alcohol used in the hydrolysis. MTMO is a good temporary protector against electro-galvanized steel corrosion in high humidity environment but it is less effective in environments containing aggressive ions such as $\mathrm{Cl}^{-}$and $\mathrm{SO}_{4}{ }^{-2}$.

In a second stage, pretreated samples were coated with an alkyd anticorrosive paint and exposed to the salt spray chamber. Dry adhesion tests as well as SEM and EDS studies were also done in order to know the nature of the disbonding fails (adhesion or cohesion).
\end{abstract}

(c) 2015 Elsevier Ltd. All rights reserved.

\section{Introduction}

The electro-galvanized steel is used in a wide range of consumer goods. It can be painted for aesthetic reasons or due to consumer demand. The combination of paint and galvanized steel is known as duplex system and has a synergistic effect because its useful service life is greater than the sum of the galvanized steel or painted steel systems considered separately [1-3].

After applying the zinc coating on the steel substrate, the surface is very active, so, in order to prevent the formation of zinc oxides and hydroxides during storage and until the product is put in service a pretreatment is applied. In most cases, the galvanized steel will be painted, demanding the pretreatment to be a suitable adhesion promoter. Although direct correlation between adhesion strength and corrosion protection seems not to exist, the maintenance of some adhesion level is necessary for preventing corrosion progress or at least to delay the access of aggressive species to metal substrate and

\footnotetext{
* Corresponding author.

E-mail address: estelectro2@cidepint.gov.ar (C. Deyá).

${ }^{1}$ Tel.: +54 221483 1142; fax: +54221 4271537 .
}

the diffusion along the metal/coating interface [4,5]. The most efficient pretreatments used as corrosion temporary protection and/or adhesion promoters of galvanized steel are based on $\mathrm{Cr}$ (VI) and zinc phosphate [6]. However, the high toxicity and carcinogenic nature of the $\mathrm{Cr}(\mathrm{VI})$ creates the necessity to look for new environmental-friendly alternatives as replacement [7-11]. In this sense, pretreatments with functionalized silane solutions rise as an alternative because they are not toxic and can form a protective barrier on the metal. The protection capacity of this barrier depends not only on the film thickness and porosity but also on the silane nature [12-17]. Although silane films do not provide the self-healing effect afforded by the $\mathrm{Cr}(\mathrm{VI})$ ions, these properties can be given by the addition of anticorrosive ions such as cerium [18-23]. Also, silanes films are harder, more resistant to erosion and show good thermal stability.

In general, the silane is hydrolyzed before its application to the substrate in order to form silanol groups, Fig. 1a. Silane adheres to the metal substrate by covalent bonds resulting from the reaction between the silanol formed during the hydrolysis and the oxideshydroxides groups present on the metal surface, Fig. 1b $[18,22,24,25]$. 
a
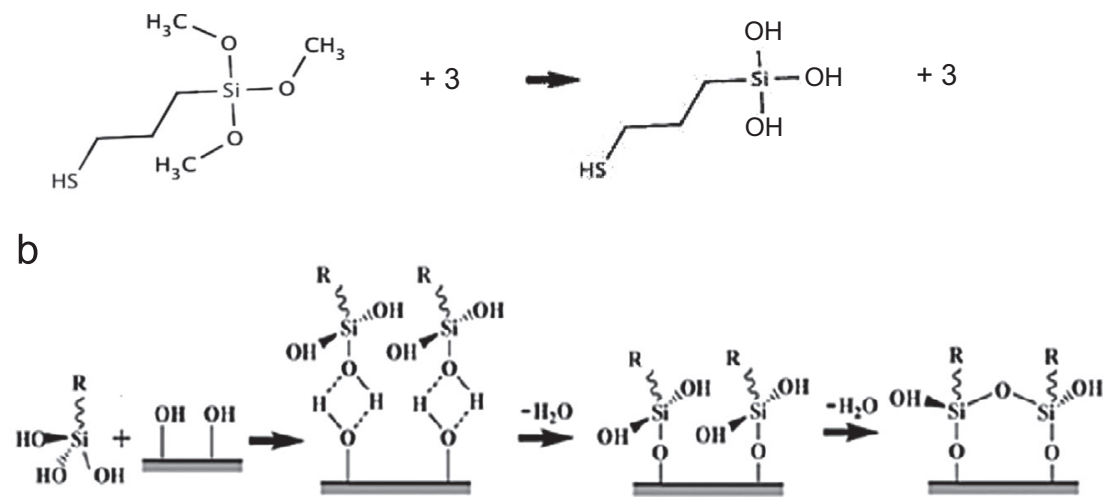

Fig. 1. a) Hydrolysis of MTMO; and b) Adhesion mechanism of the silane to the metal substrate.

The aim of this work was to evaluate the use of methanol or ethanol as a component of the hydrolysis solvent and to study the time and temperature influence of the curing process on the final silane film properties.

The porosity of the obtained films was evaluated by cyclic voltammetry $(\mathrm{CV})$, the protective performance by polarization curves and by exposure tests in humidity and prohesion chambers (HC and PC, respectively). In these cases, the corrosion degree was evaluated as a function of the exposure time. Finally, the film morphology and composition were characterized by scanning electron microscopy (SEM) and energy dispersive spectroscopy (EDS). For comparison purpose uncoated electro-galvanized steel sheets (EG) were also tested.

In a second stage, silane pretreated samples coated with alkyd paint were exposed to the salt spray chamber (SSC) to evaluate the corrosion behavior of duplex systems. Dry adhesion was assessed and, after the corrosion test, the area underneath the removed paint was observed by SEM and studied by EDS to know the nature of the failure (adhesion or cohesion).

\section{Experimental details}

\subsection{Zinc electrodeposition}

SAE 1010 steel coupons ( $40 \mathrm{~mm}$ x $80 \mathrm{~mm}$ x 0,7 mm) were electrochemically cleaned in $20 \%(\mathrm{w} / \mathrm{v}) \mathrm{NaOH}$ at $30 \mathrm{~A} / \mathrm{dm}^{2}$ for $20 \mathrm{~s}$ at $22 \pm 1{ }^{\circ} \mathrm{C}$, pickled with $30 \%(\mathrm{w} / \mathrm{v}) \mathrm{HCl}$ solution at the same temperature, and washed with distilled water. After cleaning and pickling, the samples were electro-galvanized in acid $(\mathrm{pH}=2)$ $\mathrm{Zn}_{2} \mathrm{SO}_{4}$ electrolyte $\left(90 \mathrm{~g} / \mathrm{L}\right.$ of $\left.\mathrm{Zn}^{+2}\right)$ at $40 \mathrm{~A} / \mathrm{dm}^{2}$ for $20 \mathrm{~s}$ giving a uniform $7 \mu \mathrm{m}$ zinc coating, determined by gravimetry.

\subsection{Sol-gel pretreatment}

\subsubsection{Methanol/water solvent mixture}

The silane suspension was prepared by dissolving two volumes of MTMO in three volumes of methanol/water solution $(1.5 / 1 \mathrm{v} / \mathrm{v})[26] . \mathrm{pH}$ of the methanol/water solution was previously adjusted to 4 with acetic acid. The suspension was stirred at $22 \pm 1{ }^{\circ} \mathrm{C}$ for $1 \mathrm{~h}$ in order to complete the dissolution process [25]. After reaction, a tenfold dilution with the same methanol/water solution was done [26]. The final concentration of MTMO was $4 \% \mathrm{v} / \mathrm{v}$.

Finally, some electro-galvanized steel sheets were immersed in the solution for $1 \mathrm{~min}$. The samples were then distributed in three groups to be cured in an oven at different conditions: (a) $80 \pm 2{ }^{\circ} \mathrm{C}$ for $10 \mathrm{~min}$; (b) $100 \pm 2{ }^{\circ} \mathrm{C}$ for $10 \mathrm{~min}$, and (c) $20^{\circ} \mathrm{C}$ for 2 days.
Table 1

Processes of silane application, curing conditions and samples identification.

\begin{tabular}{lllll}
\hline Hydrolysis solvent & \multicolumn{2}{l}{ Curing conditions } & $\begin{array}{l}\text { Sample } \\
\text { code }\end{array}$ & $\begin{array}{l}\text { Painted } \\
\text { sample code }\end{array}$ \\
\cline { 2 - 3 } & Temperature $\left({ }^{\circ} \mathbf{C}\right)$ & Time & & \\
\hline Methanol/water & 20 & 2 days & M2 & PM2 \\
& 80 & 10 min & M8 & PM8 \\
& 100 & 10 min & M10 & PE10 \\
Ethanol/ water & 20 & 2 days & E2 & PE2 \\
& 80 & 10 min & E8 & PE8 \\
& 100 & 10 min & E10 & PE10 \\
$\begin{array}{c}\text { Control coupons } \\
\text { (electro-galvanized }\end{array}$ & - & - & EG & PEG \\
steel) & & & & \\
\end{tabular}

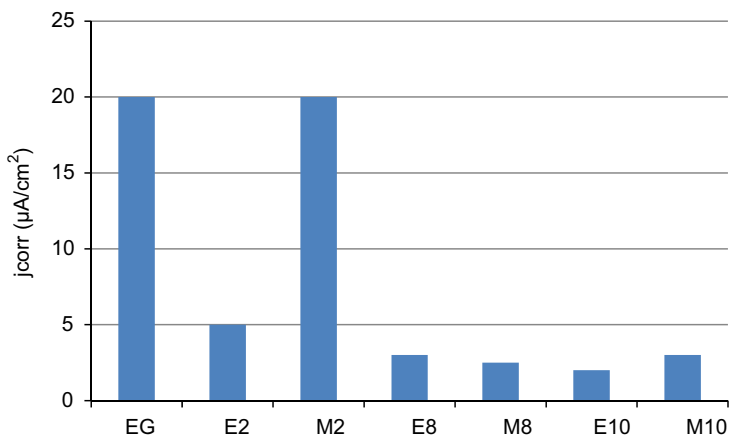

Fig. 2. Corrosion current density $\left(J_{\text {corr }}\right)$ of bare and pretreated samples.

\subsubsection{Ethanol/water solvent mixture}

The MTMO hydrolysis was also done in ethanol/water $(15 / 1 \mathrm{v} / \mathrm{v})$ solution [27]. In this case, $4 \%(\mathrm{v} / \mathrm{v})$ MTMO was hydrolyzed in the solvent mixture at $22 \pm 1{ }^{\circ} \mathrm{C}$ for $1 \mathrm{~h}$. The $\mathrm{pH}$ of the ethanol/water solution was adjusted to 4 with acetic acid. The electro-galvanized steel sheets were immersed in the MTMO solution for $1 \mathrm{~min}$ and then cured in an oven considering the same conditions indicated in the previous paragraph.

The used solvents mixtures, curing conditions, samples code and painted samples code are presented in Table 1.

\subsection{Pretreated samples}

\subsubsection{Cyclic voltammetry and polarization curves}

As recommended by Titz et al. [28], CV was performed in aerated borate solution $\left(35 \mathrm{~g} / \mathrm{L}\right.$ of $\mathrm{H}_{3} \mathrm{BO}_{3}$ and $40 \mathrm{~g} / \mathrm{L}$ of $\mathrm{Na}_{2} \mathrm{~B}_{4} \mathrm{O}_{7} \cdot 10 \mathrm{H}_{2} \mathrm{O}$ ) from -1500 to $0 \mathrm{mV}$ versus saturated calomel electrode (SCE) with a scan rate of $100 \mathrm{mV} / \mathrm{s}$. In this electrolyte, the 

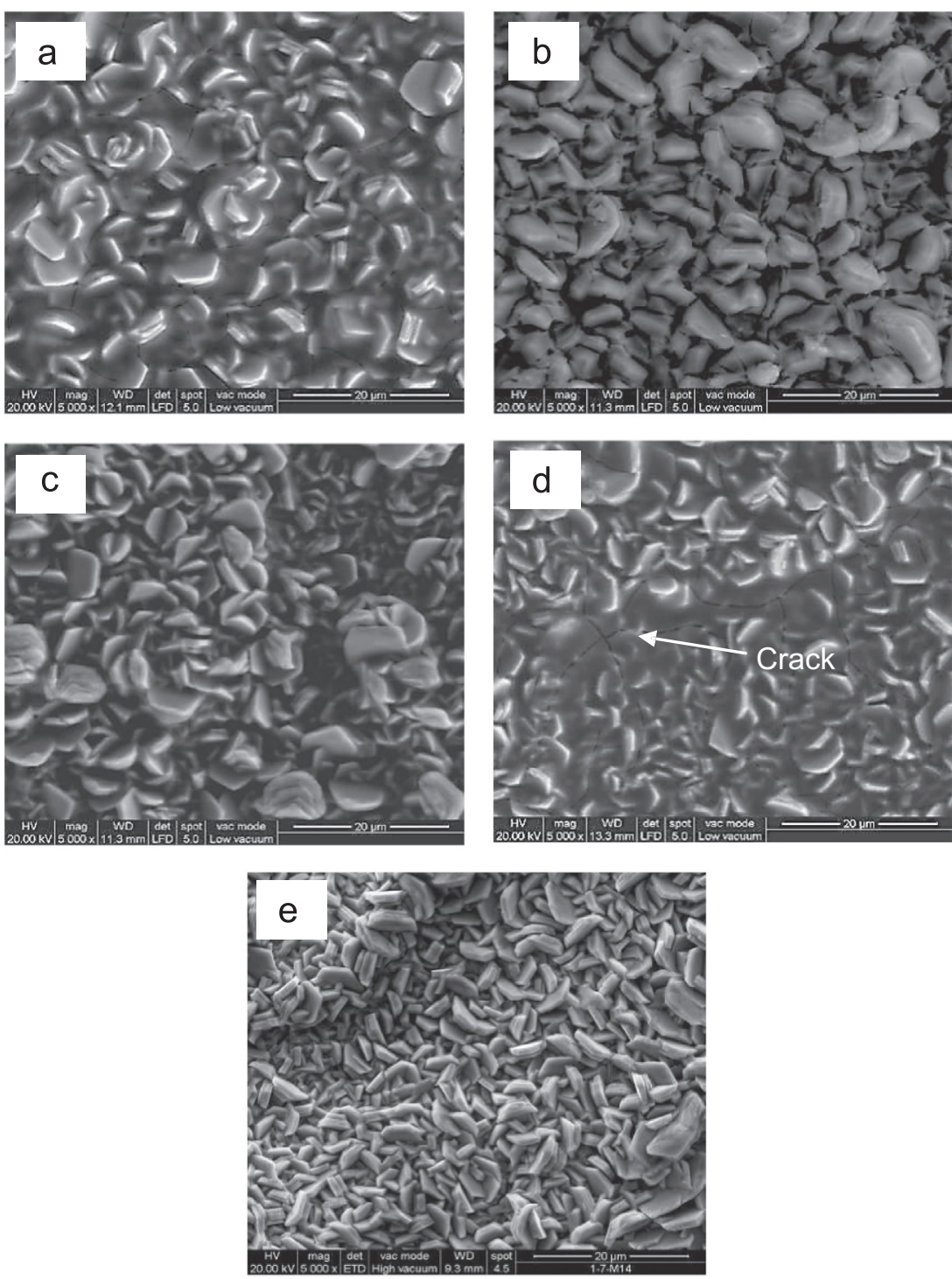

Fig. 3. Microphotographs of the pretreated samples $(5000 \times)$. a) M8; b) E8; c) M10; d) E10; e) EG.

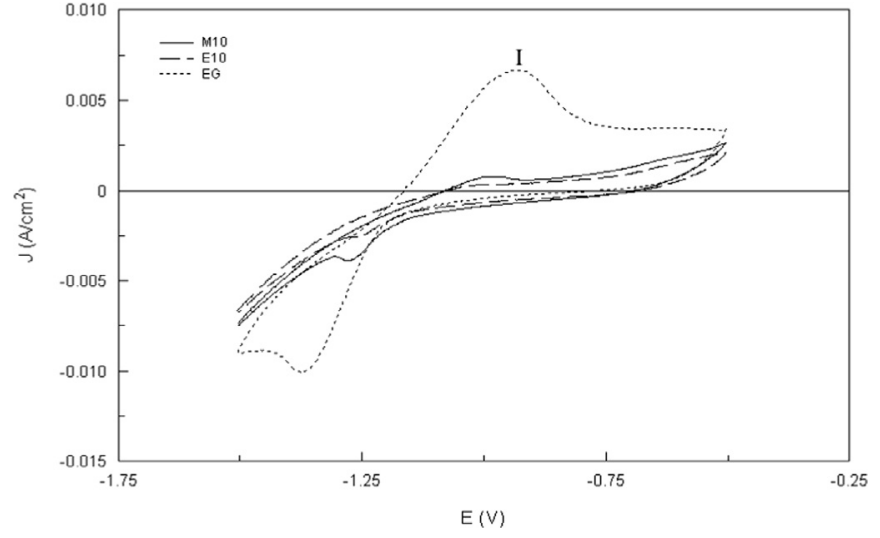

Fig. 4. Cyclic voltammetry of the M10, E10 and EG samples.

current density curves for zinc electrodes showed a dissolution anodic peak followed by a passive region. Integration of this peak gave an anodic charge proportional to the active $\mathrm{Zn}$ surface area. Therefore, as the silane-based coating protects the substrate only as a physical barrier, the coating porosity may be evaluated by this technique [29].

Polarization curves in $0.05 \mathrm{M} \mathrm{NaCl}$ solution at $22 \pm 1{ }^{\circ} \mathrm{C}$, with a potential sweep rate of $0.166 \mathrm{mV} / \mathrm{s}$ in the range $\pm 50 \mathrm{mV}$ from the open circuit potential (OCP) were obtained by a Potentiostat/Galvanostat PAR $273 \mathrm{~A}$ controlled by the CorrWear ${ }^{\circledR}$ software. The working electrode (pretreated electro-galvanized steel sheets) area was $1 \mathrm{~cm}^{2}$. A Pt ring of great area and a SCE were used as counter and reference electrodes, respectively. The corrosion current density $\left(\mathrm{J}_{\text {corr }}\right)$ was determined by linear extrapolation of the anodic E vs. J curves at the corrosion potential (OCP) [22,30-32]. Before each polarization run, the immersed working electrode was kept at rest until a stable OCP reading was obtained.

Three replicates were tested.

\subsubsection{Film examination and characterization}

The pretreated samples were observed by SEM, while the protective film composition was characterized by EDS using a FEI Quanta $200^{\circledR}$ microscope with electron detector Apollo $40^{\circledR}$ and EDAX $^{\circledR}$ detector. 

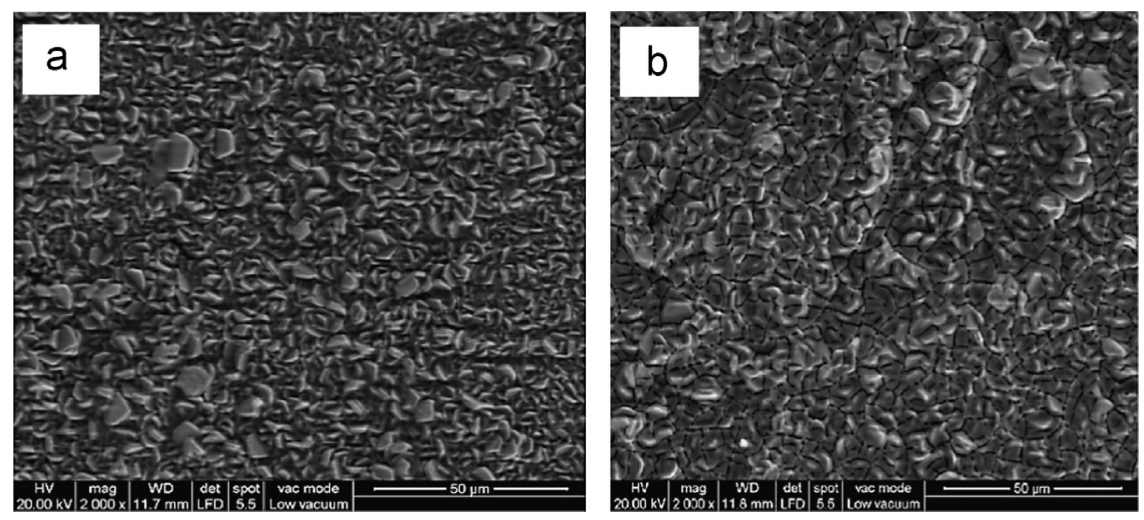

Fig. 5. Microphotographs of the pretreated samples $(2000 \times)$. a) M2; b) E2.

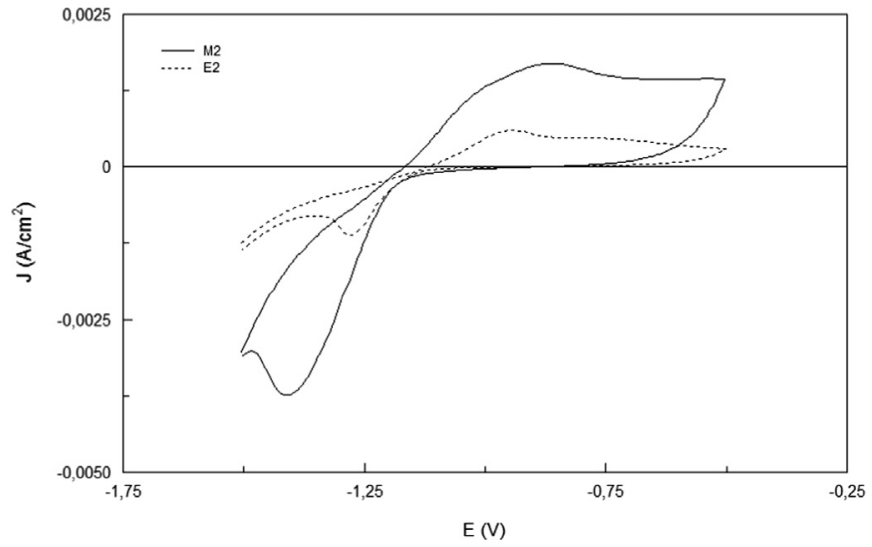

Fig. 6. Cyclic voltammetry of the M2 and E2 samples.

Table 2

Summary of some results.

\begin{tabular}{|c|c|c|c|c|}
\hline Sample & \multicolumn{2}{|c|}{ Film morphology } & \multirow{2}{*}{$\begin{array}{l}\text { Painted sam- } \\
\text { ple code }\end{array}$} & \multirow{2}{*}{$\begin{array}{l}\text { Adhesion failure } \\
\text { Chemical interaction; } \\
\text { failure for cohesion }\end{array}$} \\
\hline M2 & Thin & $\begin{array}{l}\text { No cracks but } \\
\text { pores }\end{array}$ & & \\
\hline M8 & \multirow{5}{*}{ Thick } & Cracks & PM8 & \multirow{5}{*}{$\begin{array}{l}\text { Physical interaction; } \\
\text { silane-paint failure }\end{array}$} \\
\hline M10 & & Few cracks & PM10 & \\
\hline E2 & & Cracks & PE2 & \\
\hline E8 & & $\begin{array}{l}\text { Completelly } \\
\text { cracked }\end{array}$ & PE8 & \\
\hline E10 & & Few cracks & PE10 & \\
\hline
\end{tabular}

\subsubsection{Exposure to environmental chambers}

To simulate storage conditions the samples were placed in the laboratory at controlled conditions of $20^{\circ} \mathrm{C}$ and $80 \%$ relative humidity for 85 days. Three replicates of the different sample types were then placed in the HC (ASTM D2247 standard) or in the PC (ASTM G85-A5 standard) for $264 \mathrm{~h}$. The prohesion test included the exposure to alternating cycles with $\mathrm{NaCl} 0.05 \%(\mathrm{w} / \mathrm{v})$ and $\left(\mathrm{NH}_{4}\right)_{2} \mathrm{SO}_{4} 0.35 \%(\mathrm{w} / \mathrm{v})$ spray at $25{ }^{\circ} \mathrm{C}$ followed by heating up to $35^{\circ} \mathrm{C}$. This chamber simulates an urban-industrial environment.

In both chambers the corrosion degree (ASTM D610 standard) was evaluated. Bare electro-galvanized steels panels were also exposed as controls.

\subsection{Painted samples}

A set of the pretreated samples was coated with an alkyd paint to evaluate the duplex system corrosion behavior. The paint composition was: $9.4 \%$ of zinc molybdophosphate as anticorrosive pigment, $3.8 \%$ of $\mathrm{TiO}_{2}, 9.1 \%$ of talc, $9.1 \%$ of barium sulfate, $43.6 \%$ of alkyd resin (1:1) and $25 \%$ of mineral spirit, by volume. The dried paint thickness $(80 \pm 5 \mu \mathrm{m})$ was measured by a coating thickness gauge from Schwyz.

\subsubsection{Assays on painted panels}

Dried adhesion tests were conducted by tape test (ASTM D 3359 standard) and impact (ASTM D 2794 standard) methods.

The samples were placed in the SSC (ASTM B117 standard) for 49 days. The corrosion and/or blistering degrees (ASTM D610 or ASTM D714 standards, respectively) were evaluated over time.

\section{Results and discussion}

\subsection{Pretreated samples}

The polarization curves performed on bare and pretreated samples cured at $80^{\circ} \mathrm{C}$ or $100{ }^{\circ} \mathrm{C}$ show that the corrosion current density of the treated samples is around one order of magnitude less than the corresponding to the bare electrogalvanized samples (Fig. 2); no significant effect of the solvent hydrolysis or curing conditions was observed. However, SEM images of those samples display that the film morphology was highly dependent on both, the co-solvent hydrolysis and the curing temperature (Fig. 3). When cured at $80^{\circ} \mathrm{C}$, the films obtained using methanol as co-solvent exhibit very thin cracks $(\approx 0.2 \mu \mathrm{m})$ while those built-up in ethanol seemed to be not only thicker but also completely cracked, Fig. 3a and b, respectively.

The increase of $20^{\circ} \mathrm{C}$ in the curing temperature produced morphological changes. The films observed on M10 and E10 samples show less cracks than those on M8 and E8 samples, Fig. $3 c$ and d, respectively. For comparison purposes, Fig. 3e shows the SEM image of the bare metal substrate. Cracks occur during the polymerization process due to internal stresses generated within the coating, especially in hard films. Hydrolyzed with ethanol, the coatings are thicker but have higher level of cracks that do not reach the zinc substrate. This is evidenced by the results obtained in the cyclic voltammetry, where in samples cured at $100{ }^{\circ} \mathrm{C}$, the area under the curve of the anodic peak (I) for both alcohols is similar and negligible compared to that of the EG sample, Fig. 4. This indicates that the porosity of the two coatings is similar and, therefore $\mathrm{J}_{\text {corr }}$ values are also similar since these coatings protect the substrate only by physical barrier effect. The film composition obtained by EDS was similar for both coatings hydrolyzed with methanol or ethanol as co-solvent $(\mathrm{C} / \mathrm{Si} / \mathrm{S}=1.0-2.9 / 1.0 / 0.6-0.7)$. 
a
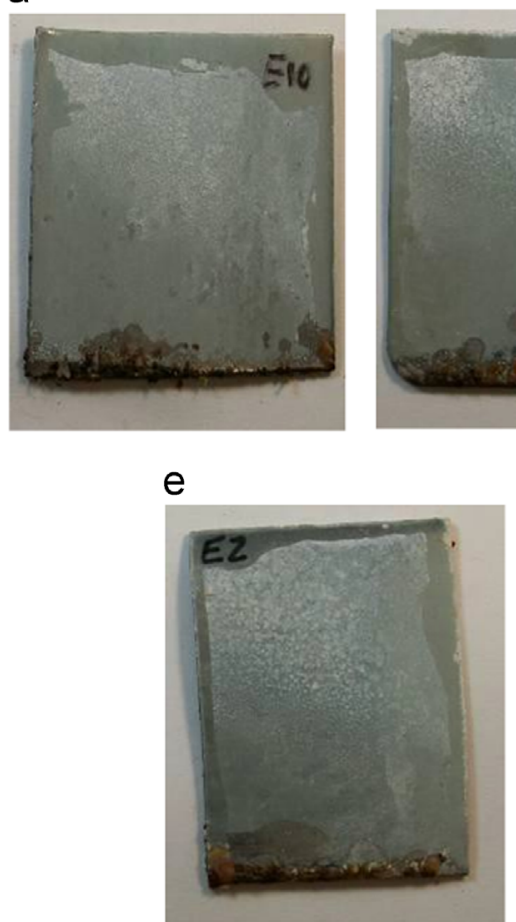

b

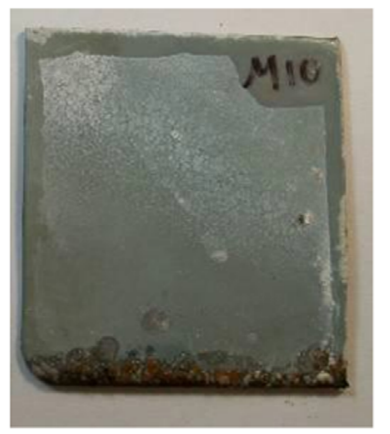

f

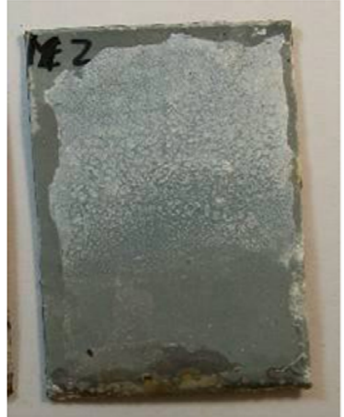

C

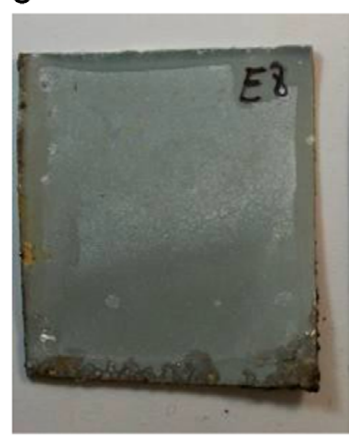

g

d
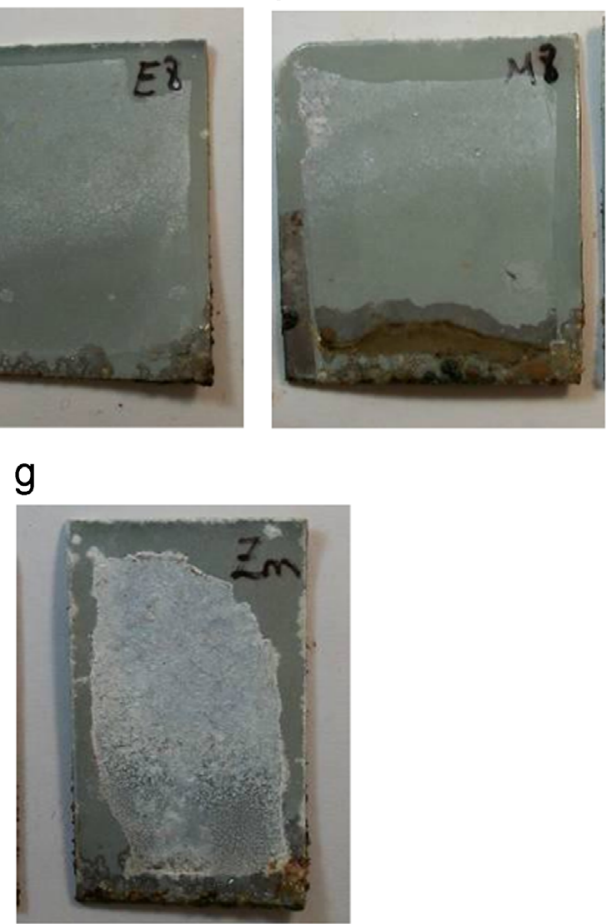

Fig. 7. Photographs of the pretreated samples after $264 \mathrm{~h}$ of exposure in the HC. a) E10;, b) M10; c) E8; d) M8; e) E2; f) M2; g) EG.

a

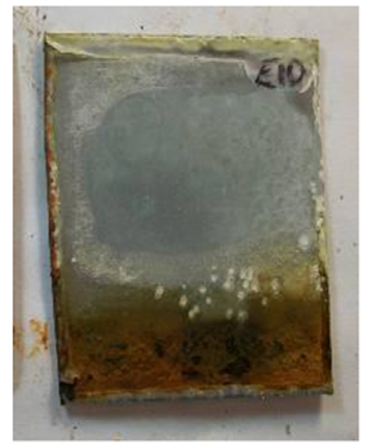

e

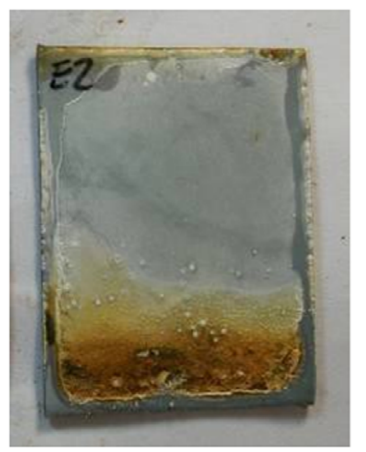

b

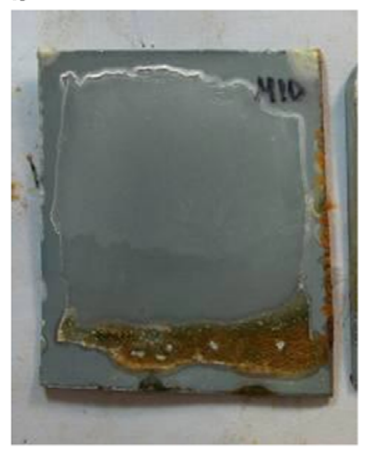

f

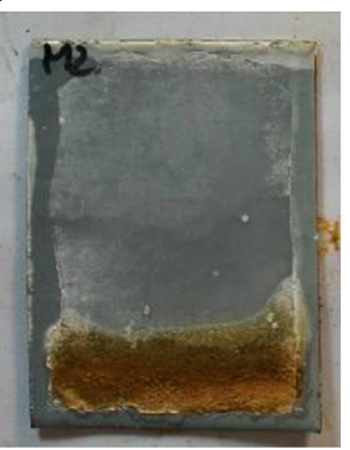

C

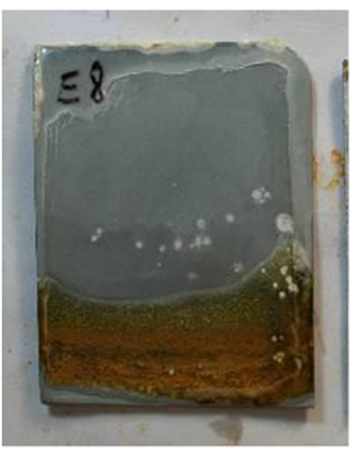

g d

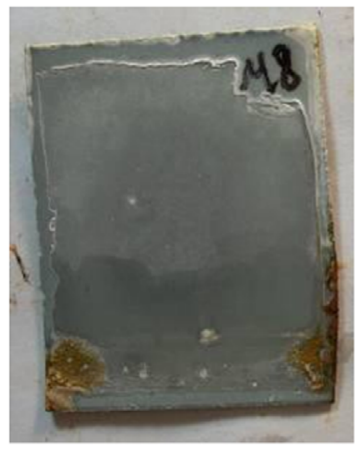

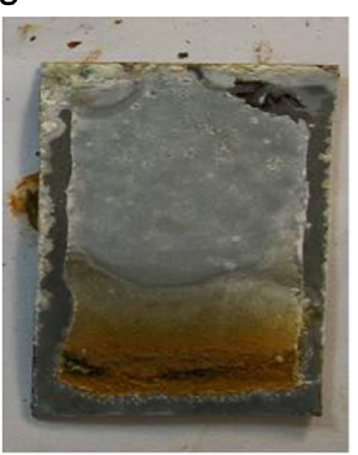

Fig. 8. Photographs of the pretreated samples after 264 h exposure in the PC. a) E10; b) M10; c) E8; d) M8; e) E2; f) M2; g) EG.

Fig. 2 shows that the corrosion behavior of M2 and E2 samples was quite different as a function of the used co-solvent. M2 seemed to be unprotected, $J_{\text {corr }}(\mathrm{M} 2) \cong J_{\text {corr }}(E G)$, whereas E2 samples showed a substantial protection level, $J_{\text {corr }}(E 2) \cong 0.25 \times J_{\text {corr }}(E G)$. On the surface of M2 samples, the zinc structure is clearly observed (Fig. 5a), indicating that the coating formed was very thin. No cracks were observed at higher magnification, but the film may have a high density of nanopores, which is evidenced by the $J_{\text {corr }}$ values as well as by the presence of the anodic peak in the cyclic voltammetry, Fig. 6. However, E2 samples showed thicker coatings and micro-cracks, Fig. 5b.

Some of these results are presented in Table 2. The differences between replicates were less than $1 \%$. 
a
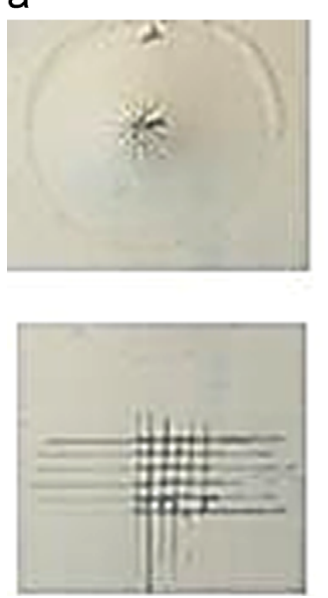

b
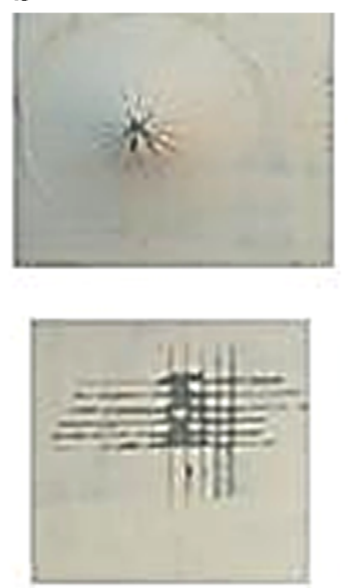

c
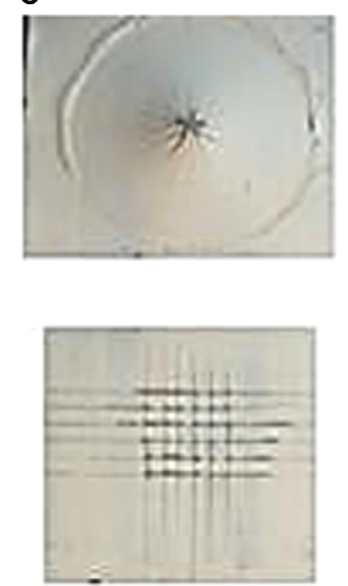

d
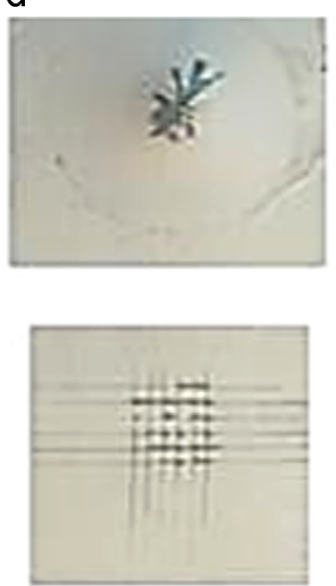

e
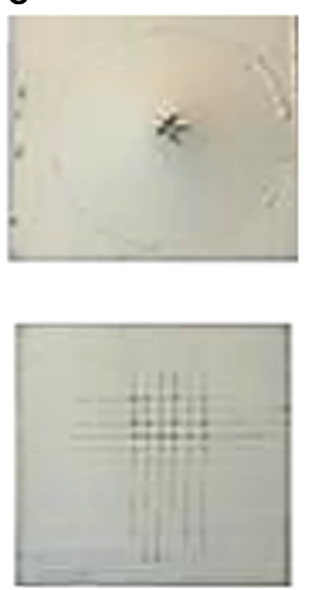

Fig. 9. Results of the dry adhesion tests (above: impact test; below: tape test). a) PM10; b) PE10; c) PE2; d) PM2; e) PEG.

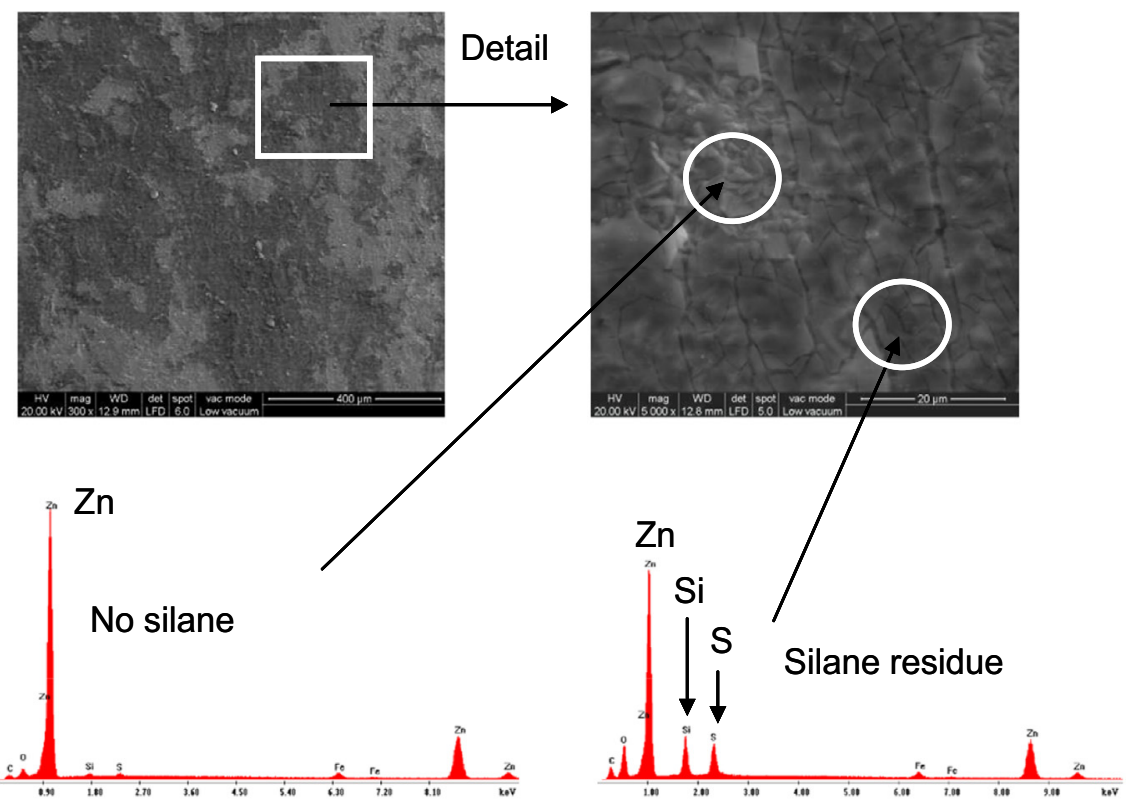

Fig. 10. SEM and EDS of the paint underneath area after adhesion test in PE8 sample.

After $264 \mathrm{~h}$ of exposure in $\mathrm{HC}$ the samples cured at $80^{\circ} \mathrm{C}$ or $100{ }^{\circ} \mathrm{C}$ (hydrolyzed with methanol or ethanol) presented the best performance. Of the samples cured at $20^{\circ} \mathrm{C}$, E2 had a slightly better performance than M2. Finally, the sample without pretreatment showed the worst performance, Fig. 7. In EG samples some iron corrosion products could be observed, which would be indicative of a certain loss of galvanic protection.

Under prohesion exposure conditions, especially the M8 and M10 samples cured at high temperatures, exhibited better corrosion performance than the rest of the tested ones while the E8 and E10 samples behaved quite similar to EG ones, Fig. 8.

\subsection{Painted samples}

Paint-silane adhesion would be the result of two effects: the first is related to the covalent bonds between the silane and the alkyd resin, and the second to the paint capability of penetrating the silane film between the cracks and thus to get better physical adhesion.

The adhesion tests showed that MTMO does not enhance the alkyd paint/electro- galvanized steel adhesion. Conversely, after

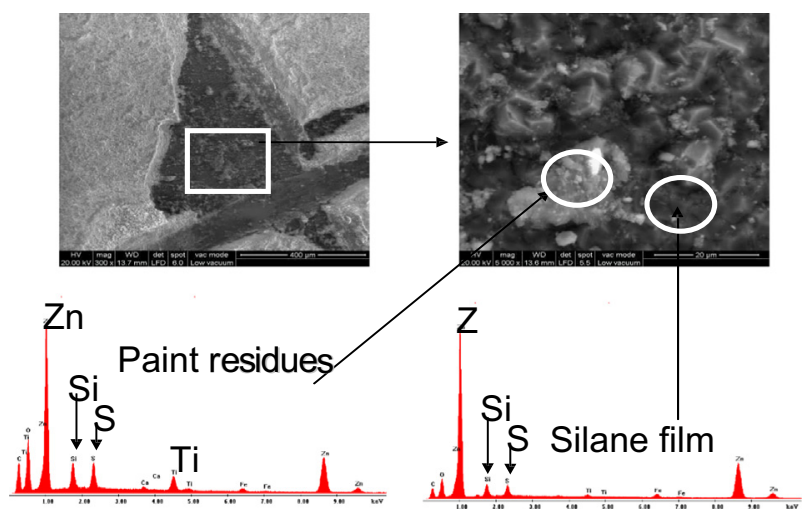

Fig. 11. SEM and EDS of the paint underneath area after adhesion test in PM8 sample.

the adhesion tests, a slightly more deteriorated coating was seen by naked eye in the pretreated samples, Fig. 9. With methanol as co-solvent, PM2 samples adhesion was similar to that of PM10 
Table 3

Evaluation of corrosion and blistering degrees of painted samples as a function of the exposure time in the SSC.

\begin{tabular}{|c|c|c|c|c|c|c|}
\hline \multirow[t]{3}{*}{ Sample } & \multicolumn{6}{|c|}{ Exposure time (h) } \\
\hline & \multicolumn{2}{|l|}{576} & \multicolumn{2}{|l|}{816} & \multicolumn{2}{|l|}{936} \\
\hline & Corrosion $^{a}$ & Blistering ${ }^{\mathrm{b}}$ & Corrosion $^{a}$ & Blistering ${ }^{\mathrm{b}}$ & Corrosion $^{a}$ & Blistering ${ }^{b}$ \\
\hline PE2 & 10 & $2 \mathrm{~F}$ & 10 & $2 \mathrm{~F}$ & 9 & $2 \mathrm{~F}$ \\
\hline PE8 & 9 & 10 & 9 & $6 \mathrm{~F}$ & 9 & $2 \mathrm{~F}$ \\
\hline PE10 & 10 & 10 & 10 & $8 \mathrm{~F}$ & 10 & $4 \mathrm{~F}$ \\
\hline PM2 & 9 & $6 \mathrm{M}$ & 9 & $2 \mathrm{M}$ & 9 & $2 \mathrm{M}$ \\
\hline PM8 & 9 & $4 \mathrm{~F}$ & 9 & $2 \mathrm{~F}$ & 9 & $2 \mathrm{~F}$ \\
\hline PM10 & 10 & 10 & 10 & $2 \mathrm{~F}$ & 10 & $2 \mathrm{~F}$ \\
\hline PEG & 10 & $4 \mathrm{M}$ & 10 & $4 \mathrm{M}$ & 9 & 4MD \\
\hline
\end{tabular}

Blisters's size: 10 , no blisters; 8 smallest sizes seen by unaided eye, $6,4,2$, sizes progressively larger.

a Corrosion degree: 10 , no rusting; 9 , less than $0.03 \%$ of surface rusted.

${ }^{\mathrm{b}}$ Blisters's frequency: MD, medium dense; M, medium; $\mathrm{F}$, few.

a

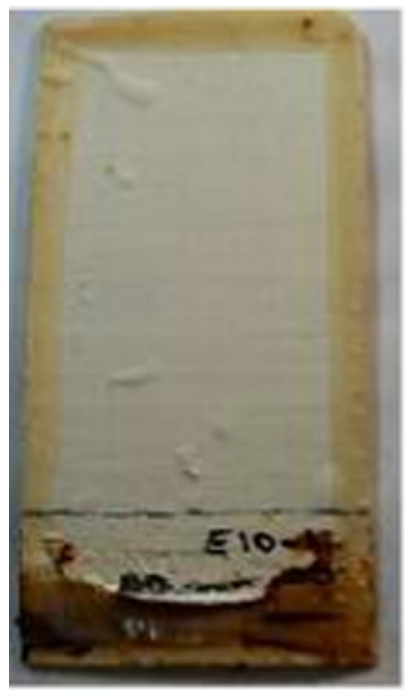

b

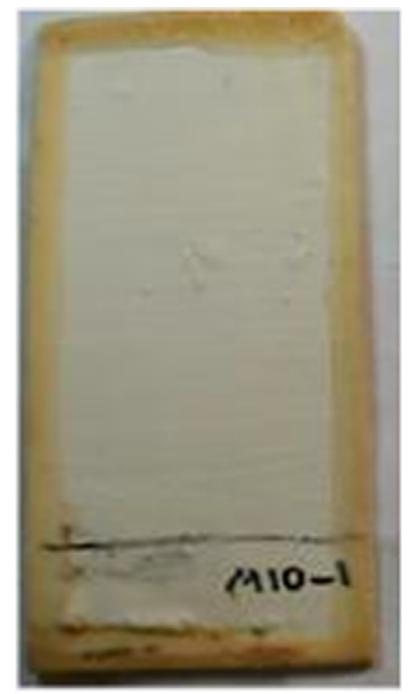

C

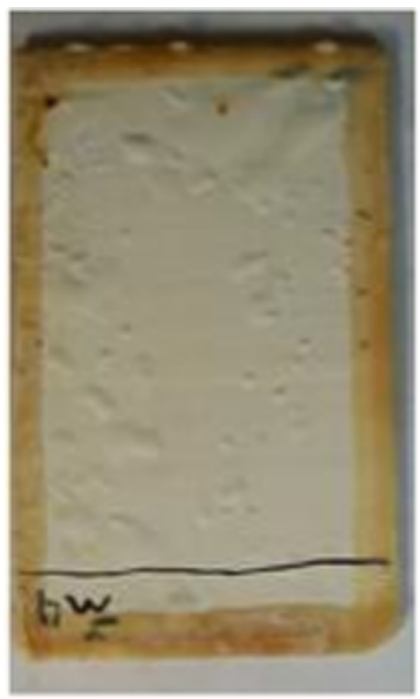

Fig. 12. Photograph of the painted samples after 936 h exposure in the SSC. a) PE10; b) PM10; c) PEG.

samples while with ethanol, PE2 samples had better adhesion than those cured at higher temperatures.

In PE8 samples, the areas under the removed paint did not display any sign of this film since no $\mathrm{Ti}$ ( from $\mathrm{TiO}_{2}$ ) was detected by EDS, Fig. 10. MTMO was present only in some parts of the surface, while in the others neither S nor Si was detected, indicating that the adhesion at the silane film/metal interface was the main failure. In PM8 samples studied by EDS the presence of Ti was detected, therefore, the failure was of cohesion, i.e. between layers of the paint film, Fig. 11.

The most important peaks of the EDS were marked.

When the ethanol/water mixture was used as hydrolysis cosolvent, the presence of cracks seemed to be more important than the chemical interactions since the higher adhesion was found in PE2 samples, i.e. where the crack number was also higher. In PE8 or PE10 samples there were fewer cracks, the paint could not interact adequately with the silane film and the silane/paint adhesion failed, Fig. 9.

If the methanol/water mixture was the hydrolysis solvent, the chemical interactions between the resin of the paint and the silane seemed to be more important independently of the film cracking degree. These chemical interactions allowed part of the paint to remain adhered to the substrate after the adhesion test; in other words, the fail was of cohesion between paint layers.

After the adhesion tests carried out by impact, SEM and EDS studies showed that on PM8 samples some traces of paint remained present while on PE8 samples only some silane traces were detected, in agreement with the tape test results.

Table 2 shows some of these results.

The evaluation of painted samples pretreated with MTMO and exposed to the SSC showed that the best protective behavior was obtained when the silane films were cured at $100^{\circ} \mathrm{C}$. In these cases, after $936 \mathrm{~h}$ of exposure no corrosion signs appeared on the painted surface, Table 3 . Under the other curing conditions, the corrosion performance was similar to PEG (control). When the blistering degree was evaluated, the pretreated samples showed blisters whose size was similar to that of those formed on the blank, however, its frequency was much lower, Fig. 12. These results indicate that the pretreatment with MTMO did not improve the dry adhesion between electro-galvanized steel and alkydbased paint, but increased the organic coating delamination resistance when it is exposed in an aggressive environment. As seen in Table 3, the co-solvent influence on the corrosion performance and blistering degree of samples cured under the same conditions was low. 


\section{Conclusions}

In high humidity environments, MTMO films provide temporary protection to electro-galvanized steel. Nevertheless, in media with $\mathrm{Cl}^{-}$and $\mathrm{SO}_{4}{ }^{-2}$ ions, the results were not satisfactory.

The temporary protective capacity provided by the MTMO improved when the effect supplied by the coating cured at $20^{\circ} \mathrm{C}$ for 2 days was compared with that obtained after curing at $80^{\circ} \mathrm{C}$ or $100{ }^{\circ} \mathrm{C}$ for $10 \mathrm{~min}$. The major difference was found when the hydrolysis was carried out with methanol. Increases ranging from 80 to $100{ }^{\circ} \mathrm{C}$ did not produce significant changes in the corrosion behavior of the system.

Taking into account that the results employing the different cosolvent were unimportant and being ethanol less toxic than methanol, its used is recommended. The MTMO incorporation to the metal/paint interface does not enhance the dry adhesion of the studied system. However, after the system was exposed to an aggressive environment, the delamination resistance of the organic coating increased.

The curing of the silane coating on electro-galvanized steel sheets at $100{ }^{\circ} \mathrm{C}$ improved the corrosion protection provided by the alkyd paint.

\section{Acknowledgments}

The authors acknowledge to Comisión de Investigaciones Científicas de la Provincia de Buenos Aires (CICPBA), Consejo Nacional de Investigaciones Científicas y Técnicas (CONICET) and Universidad Nacional de La Plata (UNLP) for their financial support to this research. The authors also thank to Andrés Campbell for the supplied of the silane.

\section{References}

[1] van Eijnsbergen JFH. Duplex Systems: Hot-Dip Galvanizing plus Painting. $1^{\text {st }}$ ed. Amsterdam: Elsevier Science; 1994.

[2] Pérez C, Collazo A, Izquierdo M, Merino P, Nóvoa XR. Comparative study between galvanised steel and three duplex systems submitted to a weathering cyclic test. Corros Sci 2002;44:481-500.

[3] del Amo B, Véleva L, Di Sarli AR, Elsner CI. Performance of coated steel systems exposed to different media: Part I. Painted galvanized steel. Prog Org Coat 2004;50:179-92.

[4] Dickie RA. Paint adhesion, corrosion protection, and interfacial chemistry. Prog Org Coat 1994:25:3-22.

[5] Seré PR, Deyá C, Elsner CI, Di Sarli AR. Behaviour of two eco-compatible duplex systems used in the construction industry against corrosion. Int J Adh Adh 2014;50:1-6.

[6] Maeda S. Surface chemistry of galvanized Steel sheets relevant to adhesion performance. Prog Org Coat 1996;28:227-38.

[7] Toxicological Profile for Chromium, Agency for Toxic Substances, U.S. Public Health Service, Report No. ASTSDR/TP-88/10. July; 1989.

[8] Directive Number 2003/53/EC of the European Parliament and Council. 18 June; 2003.
[9] Shi H, Liu F, Han E. Characterization of self-assembled nano-phase silanebased particle coating. Trans Nonferrous Met Soc China 2010:20:1928-35.

[10] Suegama PH, de Melo HG, Benedetti AV, Aoki IV. Influence of cerium (IV) ions on the mechanism of organosilane polymerization and on the improvement of its barrier properties. Electrochim Acta 2009;54:2655-62.

[11] Directive Number 2011/65/EU (RoHS2), of the European Parliament and Council, Restriction of Hazardous Substances. July; 2011.

[12] Kim HJ, Zhang J, Yoon RH, Gandour R. Development of environmentally friendly nonchrome conversion coating for electrogalvanized steel. Surf Coat Technol 2004;188-189:762-7.

[13] van Ooij WJ, Zhu D, Stacy M, Seth A, Mugada T, Gandhi J, Puomi P. Corrosion Protection Properties of Organofunctional Silanes -An Overview. Tsinghua Sci Technol 2005;10(6):639-65.

[14] Chico B, Galván JC, de la Fuente D, Morcillo M. Electrochemical impedance spectroscopy study of the effect of curing time on the early barrier properties of silane systems applied on steel substrates. Prog Org Coat 2007:60:45-53.

[15] Zaferani SH, Peikari M, Zaarei D, Danaee I, Fakhraei JM, Mohammadi M. Using Silane Films to Produce an alternative for Chromate Conversion coatings. Corrosion 2013;69(4):372-87.

[16] Khramov AN, Balbyshev VN, Voevodin NN, Donley MS. Nanostructured solgel derived conversion coatings based on epoxy- and amino-silanes. Prog Org Coat 2013;47(3-4):207-13.

[17] Andreatta F, Lanzutti A, Paussa L, Fedrizzi L. Addition of phosphates or copper nitrate in a fluotitanate conversion coating containing a silane coupling agent for aluminium alloy AA6014. Prog Org Coat 2014;77:2107-15.

[18] Twite RL, Bierwagen GP. Review of alternatives to chromate for corrosion protection of aluminum aerospace alloys. Prog Org Coat 1998:33:91-100.

[19] van Ooij W. J. Replacements of chromates: an overview. 〈http://www.sintef.no/ static/mt/norlight/ICEPAM/01-van-Ooij_Cincinnati.pdf).

[20] Montemor MF, Simões AMP, Ferreira MGS. Composition and behaviour of cerium films on galvanised steel. Prog Org Coat 2001;43:274-81.

[21] Trabelsi W, Cecilio P, Ferreira MGS, Montemor MF. Electrochemical assessment of the self-healing properties of Ce-doped silane solutions for the pretreatment of galvanised steel substrates. Prog Org Coat 2005:54:276-84.

[22] Kong G, Lu J, Wu HJ. Post treatment of silane and cerium salt as chromate replacers on galvanized steel. J Rare Earths 2009;27(1):164-8.

[23] Zaferani SH, Peikari M, Zaarer D, Danaei I. Electrochemical effects of silane pretreatments containing cerium nitrate on cathodic disbanding properties of epoxy coated steel. J Adhes Sci Technol 2013;27(22):2411-20.

[24] Wang D, Bierwagen GP. Sol-gel coatings on metals for corrosion protection. Prog Org Coat 2009;64:327-38.

[25] Bexell U, Grehk M, Olsson M, Gelius U. XPS and AES characterization of hydrolyzed $\gamma$-mercaptopropyltrimethoxysilane deposited on AlZn Al-434Zn16Si alloy coated steel. Surf Interface Anal 2004;36:624-31.

[26] Bexell U, Grehk TM. A corrosion study of hot-dip galvanized steel sheet pre- treated with $\gamma$-mercaptopropyltrimethoxysilane. Surf Coat Tech 2007;201:4734-42.

[27] Chen M-A, Lu X-B, Guo Z-H, Huang R. Influence of hydrolysis time on the structure and corrosion protective performance of (3- mercaptopropyl) triethoxysilane film on copper. Corros Sci 2011;53:2793-802.

[28] Titz T, Hörzenberger F, Van der Bergh K, Grundmeier G. Correlation of Interfacial Electrode Potential and Corrosion Resistance of Plasma Polymer Coated Galvanized Steel. Part 2: influence of forming induced defects. Corros Sci 2010;52:378-86.

[29] Seré PR, Deyá C, Egli WA, Elsner CI, Di Sarli AR. Protection of Galvanized Steel with Silanes: its comparison with Chromium(VI). J Mater Eng Perform 2014;23:342-8.

[30] Dattilo M. Polarization and corrosion of electrogalvanized steel-evaluation of zinc coatings obtained from waste-derived zinc electrolytes. J Electrochem Soc $1985 ; 132: 2557-61$

[31] Zhang XG. Corrosion and Electrochemistry of Zinc. $1^{\text {st }}$ edition. New York: Plenum Press; 1996 SBN 0-306-45334-7.

[32] Capelossi VR, Aoki IV. Influence of sonication on anticorrosion properties of a sulfursilane film dopped with Ce (IV) on galvannealed steel. Prog Org Coat 2013;76:812-20. 